\title{
A PESQUISA E O FAZER PEDAGÓGICO : GERAR E DIFUNDIR CONHECIMENTOS
}

\author{
Prof.a M s. Romilda Teodora EN S* \\ Prof. a Nara Regina PLOHARSKI** \\ Prof. - SuelyT herezinha Costa SALLES***
}

\section{Resumo}

0 presente artigo relata a proposta na PU CPR de unir pesquisa e docência na formação continuada de professores, mais especificamente dos estudos sobre a abordagem qualitativa e a metodologia da pesquisa que está sendo utilizada no projeto G estão Estratégica de Competências e a Formação do Professor. A realização da pesquisa vem propiciando ao grupo de professores da área de educação um trabal ho integrado, e ao mesmo tempo, um caminhar pela pesquisa-ação, integrando os seguintes procedimentos etécnicas de pesquisa: análise documental, análise iconográfica, aplicação de questionários, entrevista semi-estruturada, observação participante e seminários.

Palavras-chave: pesquisa, metodologia da pesquisa, pesquisa-ação, procedimentos, técnicas de pesquisa.

\section{Resumén}

EI presente artículo relata una propuesta en la PUCPR de relacionar investigación y docencia en la formación continua de profesores, más específicamente de los estudios acerca del abordaje decalidad y la metodología de la investigación que viene siendo desarrollado en el proyecto "G estión Estratégica de Competencias y la Formación del Profesor". La investigación intenta auxiliar al grupo de docentes del area educacional un trabajo integrado, y a la vez un caminar por medio de la investigación-acción integrando los procedimientos e técnicas de investigación: analisis documental, analisis iconográfica, aplicación de cuestionarios, entrevista semi-estructurada, observación participante y seminarios.

Palabras llave: investigación, metodología de la investigación, investigaciónacción, procedimientos, técnicas de investigación

\footnotetext{
* Professora / Pesquisadora do Curso de Pedagogia da PU CPR.

** M estranda em Educação/Professora / Pesquisadora do Curso de Pedagogia da PU CPR.

*** Professora / Pesquisadora do Curso de Pedagogia da PU CPR.

Participação da Bolsista PIBIC - Lilian M aria Zanon.
} 


\section{Introdução}

Pensar as razões que levam pesquisadores a pesquisar, a investigar é um questionamento com quenos deparamos freqüentemente. ALARCÃO (2001, p. 135), nos mostra que podemos encontrar diferentes respostas, tais como: publicar e progredir na profissão de professor universitário, criar uma teoria e ser conhecida, criar conhecimento que possa ajudar o trabal ho de profissionais ou que possa mel horar a vida em sociedade, conhecer a real idade e até para simplesmente obter um título de especialista, mestre ou doutor. Temos que admitir que:

0 modo como se investiga a realidade, a relação assumida pelo investigador diante da realidade que se quer conhecer e a posição entre realidade e representação da mesma têm estado na base de posições investigativas diferenciadas. M enos estudado tem sido o modo como se intervém na realidade e como se difunde 0 saber. (ALARCÃO, 2001, p. 136)

Estas razões podem estar relacionadas às profundas mudanças verificadas no mundo atual e, a exigência que vimosfazendo à educação superior, estabelecidas na D eclaração M undial sobre Educação Superior no Século XXI: Visão e Ação, em Paris, 9 de outubro de 1998, art. 1‥ "A missão de educar, formar e realizar pesquisas" e, para dar conta de suas missões e funções, é imprescindível um projeto pedagógico que privilegie a pesquisa como um processo voltado à formação de competências de professores que formam professores. Estes precisam ser profissionais competentes e não competitivos, embora a sociedade seja competitiva. N esse contexto, a área de educação da PU CPR vem desenvolvendo projetos integrados de pesquisa, dos quais participam professores da graduação e da pós-graduação, procurando, assim, superar os desafios e os compromissos que uma instituição educacional de ensino superior deve assumir ao buscar viabilizar a concretização das competências indispensáveis ao profissional deste século, utilizando como ferramenta básica, desse processo, a pesquisa na construção do conhecimento necessário ao levantamento de subsídios para a melhoria da qualidade da universidade.

A execução de projetos integrados de pesquisa procura dar conta de outro sintoma do mundo atual, o de viver a sociedade do conhecimento ou como coloca Peter Senge (2001), a "sociedade aprendente" e o de procurar superar a aparente simplificação das tarefas colocadas pela pós-modernidade. Para isso, é imprescindível que os professores façam uso da pesquisa como ferramenta básica que dará conta de um novo modelo de divisão do trabalho ancorado nos novos padrões de sociabilidade, ou seja, na indissociabilidade entre teoria e prática. 
Q uando pesquisamos, não podemos deixar de reconhecer e aceitar a complexidade da realidade e a dificuldade em dar conta às suas manifestações. $M$ as, não esquecemos que promover, gerar e difundir conhecimento por meio da pesquisa, que é parte da atividade do ensino superior.

A complexidade que envolve educação-pesquisa fez com que procurássemos enfocar, neste artigo, a experiência com a metodologia vivenciada pelo grupo de pesquisa G estão e Políticas Públicas no Ensino Superior.

\section{Uma breve leitura dos Cursos de Formação de Professores - Licenciaturas.}

É deconhecimento geral a necessidade de um novo paradigma nos cursos de formação de professores - Licenciaturas e, isso não apenas em Curitiba, mas no Paraná, Região Sul, Brasil e América Latina para que os futuros professores se tornem competitivos no mercado internacional, principalmente se considerarmos o impacto da globalização associado à revolução tecnológica, quando vemos que o professor, ao sair da universidade, confronta-se com uma realidade na qual o conhecimento, por ele adquirido durantetodos os anos da graduação, ficaram apenas na teoria, tornaram-se obsoletos, porque faltou a vivência paralela, a prática.

Se pensarmos em nossas universidades como um todo, de forma generalizada, sem dúvida al guma podemos afirmar que o modelo vigente de formação do professor é falido. Confirmando, TARDIF, (1999, p. 17), diz: "ainda hoje, a maioria dos professores aprendem a trabalhar na prática, às apalpadelas, por tentativa e erro."

C omo a universidade poderia socorrer essa situação, ou seja, não permitir que isso acontecesse? A resposta é simples, bastaria que os mestres saíssem de seu mundo, da volta de seu umbigo e visitassem as diferentes áreas de conhe cimento. Pois, é preciso formar os alunos para o mercado de trabal ho e para a cidadania, e principalmente para o impacto da globalização junto à revolução tecnológica, ou quem sabe, para a mudança de paradigma neoliberal queé marca registrada hoje em nossas universidades.

Entre tantas coisas, tantas urgências, precisamos rever os saberes que estão envolvidos no processo educativo da formação do professor. $\mathrm{Na}$ verdade, podemos ver o processo educativo apenas como ponto de passagem ou como ponto de partida ou de chegada. Se o considerarmos, como ponto de passagem, concluiremos que são os saberes que determinam a formação do educador; porém, se considerarmos o processo educativo como ponto de partida ede chegada, será o problema da formação do educador que determinará os saberes que entrarão no referido processo. (SAVIAN I, 1996, p.153-154), 
N essa perspectiva, o processo educacional precisa ser ponto de partida e chegada, para que os educadores sejam capazes de responder aos problemas postos pela prática social quese desenvolvena sociedade, em particular, na sociedade brasileira. Fica claro que a formação do educador é que determina o projeto pedagógico de formação do professor, nos cursos de licenciatura.

Acreditando numa nova proposta para a formação de professores, num novo paradigma, os conhecimentos devem ser adquiridose compreendidos, apropriados, reelaborados, mediante al gumas ações, onde o impacto da gl obalização, junto à revolução tecnológica, exige um novo padrão de conhecimento: mais operativo, mais interativos, mais pragmático, mais global e mais valorativo. Surgindo essa nova concepção de conhecimento, altera-se a relação com as pessoas e a maneira de utilizá-lo. E, o conhecimento, deveacontecer mediante a ação saber fazer, saber usar e saber comunicar, ou seja, éa operacional ização, a funcionalidade e a informação à serviço do conhecimento. (M IRAN D A, 1997, p.42-43)

Com certeza, o processo de construção do conhecimento pressupõe que não basta apenas "saber", é preciso no mínimo saber fazer, saber buscar as informações necessárias, saber produzir resultados... enfim, um elenco de saberes para saber, e que antes e acima de tudo diríamos ainda se faz necessário "prédisposição" para saber, pois somente assim, com esse comportamento e essa postura, estaremos, por meio do conhecimento, agindo para modificar o sistema social vigente e dando um novo perfil à formação de professores.

Um dos grandes compromissos da U niversidade para com a sociedadeé a formação de profissionais competentes, mas também ela não está dando conta de maneira satisfatória desse compromisso. Para CASTAN H O (2000, p. 13), praticamente não aconteceram mudanças na universidade, ou seja, da "U niversidade M edieval para a do século XXI poucas coisas mudaram", ela está "cristalizada", sua rotina está "sacralizada" e não tem espaço para mudanças... Rubem Alves (1998), alerta para que se repense a produção científica da universidade, uma vez que, a preocupação e avaliação, em relação ao corpo docente, consiste no que seus mestres produzem de escritos, mesmo que seja para uma minoria de leitores... enquanto, na verdade, ela deveria preocupar-se com a maioria, com a formação do pensamento do povo, pois povo que pensa... vive melhor.

Sem saudosismo, é preciso partir para um novo paradigma de conhecimento, fazer com que nossas universidades deixem de ser obsoletas, e nossos cursos de Licenciaturas deixem de ser descontextualizados... arregaçar as mangas, deixar o medo do novo de lado, e fazer acontecer os quatro pilares da educação neste novo milênio: aprender a conhecer, aprender a fazer, aprender a viver juntos, aprender a ser. Ao assumirmos esse desafio, estaremos reformulando nossa teoria e prática... a teoria que professamos e a prática que vivenciamos, reven- 
do a nossa práxis como professores nos cursos de Licenciaturas, pesquisando e fazendo nossos al unos pesquisarem.

\section{2 - 0 que é pesquisa?}

A pesquisa, tradicionalmente, está cercada de ritos, dentre eles uma coleta de dados que contribui para a construção de um texto formal, ficando numa postura quantificadora, fazendo uso nas ciências humanas dos mesmos princípios e métodos das ciências naturais. D aí, pensar-se o pesquisador como alguém que estuda a realidade, mas não a atinge. Essa maneira de pensar a pesquisa tem privilegiado o lado formal-científico da pesquisa, além de gerar uma dicotomia entre teoria e prática.

Estudos pós-modernos enfatizam que a pesquisa, hoje, não pode mais estar apenas voltada à pós-graduação, mas também ao processo de formação em todos os níveis de escolaridade. $\mathrm{N}$ ão pode estar vinculada apenas aos poucos iluminados, que por pesquisarem afastam-se do contato direto com o aluno e até da realidade. G eralmente, esses iluminados enfurnam-se em gabinetes rodeados de livros, pensam apenas em técnicas, em estatísticas e em sofisticados softs para produzir dados ou, ainda, estão enfurnados em bibliotecas, junto ao computador, coberto de livros e longe da realidade.

0 reconhecimento da pesquisa como uma proposta que vai além dos muros da academia e da sofisticação instrumental está se fazendo de maneira cada vez mais clara na literatura brasileira. N estas últimas décadas, vem sendo consolidada uma valorização da pesquisa e de estímulo ao seu desenvolvimento junto às atividades docentes. D entre os educadores brasileiros, pode-se encontrar Pedro D emo (1991, 1994, 1995, 1996), M arli André(1992, 1994, 1995, 1997, 2001), Ivani Fazenda (1997), M enga Lüdke (1993, 1994, 2001), em todos os níveis de ensino.

Essa desmitificação da pesquisa não pretende levá-la ao oposto, ou seja, a uma banalização. 0 que se quer é confirmar o que diz Paulo Freire (1996, p. 32):

$\mathrm{N}$ ão há ensino sem pesquisa e pesquisa sem ensino. Esses quefazeres se encontram um no corpo do outro. Enquanto ensino contínuo buscando, reprocurando. Ensino porque busco, porque indaguei, porque indago e me educo. Pesquiso para conhecer o queainda não conheço e comunicar ou anunciar a novidade. 
Unir ensino e pesquisa é buscar a transformação da prática pedagógica na escola de qualquer nível de ensino: desde a educação infantil, perpassando pelo ensino fundamental e médio para chegar de maneira decisiva no ensino superior, para eliminar a reprodução e a cópia, de professores e de alunos.

É possível dizer que pesquisa é o processo de superação da reprodução, da cópia do professor e do aluno, contribuindo para que o profissional moderno seja capaz de superar 0 apenas saber fazer funcionar. Pois, esse trabal hador passa a ser portador do processo inovativo, passa a apresentar capacidademultidisciplinar e condição para avaliar situações complexas, com visão geral do processo e seja partícipe de sua própria formação permanente.

É importante ressaltar que esse profissional a partir da superação do processo de reprodução e da cópia saberá pensar e refletir sobre a realidade em que está inserido, vivendo um constante aprender a aprender para melhor agir. Para D EM O (1987, p. 23), "pesquisa éa atividade científica pela qual descobrimos a realidade". Para descobrir a realidade, é preciso questionar. No entanto, as respostas encontradas não representam resultados definitivos, mas é nesse diálogo do pesquisador com a realidade que se busca compreender e enfrentar de modo crítico e criativo as situações desafiadoras da cotidianeidade.

LÜDKE e ANDRÉ $(1986, p .1)$ explicitam que para se realizar uma pesquisa é preciso promover o confronto entre os dados, as evidências, as informações coletadas sobre determinado assunto eo conhecimento teórico acumulado a respeito dele. Esse confronto não cai do céu enem nasce do nada, ele precisa estar ancorado numa hipótese de trabalho, queéum problema que está intrigando o pesquisador e/ou grupo de pesquisadores. 0 problema éfruto de inquietações, curiosidade, questionamentos em relação à real idade como ela se apresenta.

A pesquisa, como explicita DEM O (1991, p.18), pode ser compreendida como "capacidade deelaboração própria", como "descoberta e criação" (p.29), "capacidade de questionamento" (p.34), como "diálogo" (p.36). Valendo-se dessa proposta, "não faz sentido dizer que o pesquisador surge na pós-graduação, quando pela primeira vez na vida dialoga com a realidade e escreve um trabalho científico. (...), a pesquisa começa na infância e está em toda a vida social. Educação criativa começa na e vive da pesquisa desde o primeiro dia de vida da criança". (p.44)

\section{3- As abordagens da pesquisa}

Por volta da década de 70, no século passado, principal mente da área social, os pesquisadores na busca de qual a melhor abordagem de pesquisa: quan- 
titati va ou qual itativa, fizeram uma ampla reflexão sobre a concepção dicotômica entre os termos. D urante esse impasse, al guns caracterizaram a pesquisa qualitativa na área educacional como absurda, artificial e inútil; já, outros, colocavam o enfoque qualitativo como sendo apenas um exercício especulativo, não reconhe cido pela ciência. No entanto, uma visão pós-moderna do conhecimento já não aceita mais esta interpretação.

Geralmente, o termo "pesquisa quantitativa" vem sendo usado para designar uma pesquisa na perspectiva positivista de ciência. Fazer esta associação é, no entanto, perder de vista que quantidade e qualidade estão intimamente relacionadas.

AN D RÉ (1995, p.15), explica ser necessário que se reserve "o uso desses termos (quantidade e qualidade) para designar o tipo de dado coletado". É a própria autora quem nos diz: "Eu reservaria os termos quantitativo e qualitativo para diferenciar técnicas de coleta ou, até melhor, para designar o tipo de dado obtido, eutilizaria denominações mais precisas para determinar o tipo de pesquisa realizada: histórica, descritiva, participante, etnográfica, fenomenológica etc."

$\mathrm{N}$ ão cabe aqui tentar aprofundar essa discussão, mas esclarecer que a denominação qual itativa surgiu numa tentativa de superar algumas deficiênciase limitações sentidas nas pesquisas até então desenvolvidas, principalmente na área da educação. 0 s resultados das investigações não traziam possíveis soluções aos problemas emergentes da situação educacional brasileira. Os tipos de levantamento que se faziam não ajudavam a compreender a trama intrincada na formulação de políticas no interior da escola, de uma sala de aula, das relações professor-aluno, da situação da avaliação na escola, e, muito mais.

Aspectos como este não negam sobremaneira a contribuição que a pesquisa experimental pode dar à educação. Enfatizam, sim, a necessidade de que esse tipo de pesquisa deva ser aplicado no momento em que já existem variáveis selecionadas a partir de evidências anteriores. $M$ as, assim mesmo, a previsão das relações dentro de uma determinada realidade é antecipada, apesar da realidade estar sempre em movimento, o que a caracteriza como não predeterminada. A prática de pesquisa até então exige que o pesquisador não fique ancorado apenas nos dados estatísticos. Ele precisa tomar partido ebuscar novas propostas de investigação com encaminhamentos metodológicos diferentes dos que se utilizavam.

$\mathrm{N}$ os anos 80 do século passado, a abordagem qualitativa de pesquisa em educação tornou-se muito popular entre os pesquisadores, inclusive os brasileiros. Surgiu, nesse período, um grande número de publicações associadas aos fundamentos teóricos e aos procedimentos metodológicos da pesquisa qual itativa, Bogdan eBiklen (1982), Erikson (1989), Guba eLincoln (1981), LüdkeeAndré (1986), Triviños (1987) entre outros. 
Estes estudos mostram que toda pesquisa pode apresentar, ao mesmo tempo, uma abordagem quantitativa e qualitativa, pois o conflito entre quantidade e qualidade não é mais aceito.

N essa nova perspectiva, surgem, dentro da abordagem qual itativa a pesquisa participante ${ }^{1}$, a pesquisa açãa ${ }^{2}$, a pesquisa do tipo etnográfica, 0 estudo de caso ${ }^{3}$. O s resultados das pesquisas emergidos, a partir dessa nova atitude de pesquisa, vêm colaborando para o desenvolvimento de políticas educacionais e apresentando resultados que contribuem para se pensar em soluções adequadas aos problemas educacionais e sociais.

\section{A abordagem qualitativa de pesquisa}

0 uso de metodologias qualitativas geram algumas dúvidas entre os pesquisadores na sua utilização. U ma delas diz respeito ao que real mente caracteriza uma pesquisa qual itativa. A segunda dificuldade tem surgido quando o pesquisador se questiona a respeito de que tipo de estudo é o mais adequado para sua utilização. A terceira dúvida está em como colocar rigor científico neste tipo de abordagem. A última questão que parece gerar muita dúvida está vinculada ao uso indevido do termo pesquisa qualitativa como equivalência de estudo de caso, estudo etnográfico, pesquisa participante.

U ma metodologia da pesquisa social é a pesquisa-ação. Este tipo de pesquisa está associado às diversas formas de ação coletiva que estão orientadas em função da resolução de problemas ou de objetivos de transformação. M uitas vezes esse tipo de pesquisa tem recebido o nome de intervenção.

\section{A gestão da pesquisa: uma proposta de pesquisa-ação}

A nova concepção de universidade como produtora de conhecimento, capaz de gerar competências e habilidades que refl itam as mudanças ocorridas na sociedade em decorrência do impacto das revoluções tecnológicas e dos novos padrões de conhecimento impostos pela global ização, vem sendo assumida pela PU CPR, em seu projeto pedagógico, no qual "a fecundidade do ensino vinculase à prática da pesquisa, que é mediadora da construção do conhecimento". (SEVERIN O, 1999, p.191)

A tenta a esta nova proposta e no aprimoramento de sua missão e função, para tornar-se uma universidade para o século XXI, a PU CPR direciona sua atenção e seu projeto pedagógico para os saberes que estão implícitos na forma- 
ção continuada do educador, ou seja, a pesquisa como fundamental à produção científica ao lado da atividade docente.

D entro desta proposta, aprova a partir do ano de 2000, regulamento para formação de grupos de pesquisa dos quais fazem parte professores e alunos da graduação e do mestrado.

Esses grupos vêm desenvolvendo trabal hos, numa tentativa de traduzir e comunicar aquilo quesetem produzido na esfera dos conhecimentos acadêmicose impedir o isolamento da comunidadeuniversitária, deforma quea prática educativa assuma um caráter de mediação entre a prática social e a prática social global, ou seja, aquela que será avaliada pela sociedade. (SAVIAN I, 1996, p. 154)

0 projeto, que recebe o título: Gestão Estratégica de Competências ea Formação do Professor, faz parte de um projeto maior, que une os estados da região sul e tem por objetivos:

- identificar como vem se desenvolvendo a gestão de processos voltados à formação de competências de professores que atuam nos cursos de Licenciaturas da PU CPR;

- estabelecer uma proposta de Gestão de Estratégias de Competências na Formação do Professor das Licenciaturas, a partir da análise das macro competências da instituição e das microcompetências individuais, investigando na prática desenvolvida na PU CPR:

- as diretrizes da política de formação de professores;

- o tipo de planejamento;

- grau de informação sobre as teorias educacionais que embasam tais processos;

- tipo de incentivo à atualização e aquisição de novas competências;

- avaliação continuada do desempenho dos atores do processo de formação;

- plano de formação contínua;

- plano de carreira baseado nas competências;

- política salarial associada ao desenvolvimento das competências; além de avaliar o processo como um todo e propor modelos que possam garantir o aprimoramento na formação de professores/pesquisadores.

Em relação a esta proposta de pesquisa e o caráter local das mediações, os fundamentos metodológicos utilizados buscaram na pesquisa-ação os meios de responder à problematização do objeto de pesquisa e por possibilitar a intervenção na realidade pesquisada.

A escolha desta metodologia nos permite como afirma SAN TO S (1999, 
p. 14) chegar às "idéias que presidem à observação eà experimentação são "idéias claras e simples a partir das quais se pode ascender a um conhecimento mais profundo e rigoroso (...)", em relação ao objeto de estudo, atendendo assim a complexidade do fenômeno investigado.

\section{0 que é pesquisa-ação?}

Diversos autores reconhecem Kurt Lewin como criador dessa linha de investigação. (SERRAN $0^{4}$, citada por AN D RÉ, 1995, p.31).

As idéias que impulsionam a pesquisa-ação na América Latina estão voltadas para a intencionalidade, ou seja, "é preciso produzir conhecimento não só para conhecer a realidade, mas também para transformá-la." (C OSTA,1991, p.50). N essa perspectiva, a pesquisa-ação para T H IO LLEN T (1985),

é um tipo de pesquisa social com base empírica, que é concebida e realizada em estreita associação com uma ação ou com a resolução de um problema coletivo eno qual os pesquisadores eos participantes representativos da situação ou do problema estão envolvidos de modo cooperativo ou participativo.

\section{Para M aria G lória Perez Serrano (1990) a pesquisa-ação é}

un proceso circular deinvestigatión y analisis dela realidad, en el quepartiendo de los problemas prácticos y de la óptica de quien los vive procedemos una reflexión y actuación problemática com objeto de mejorarla, implicando en el proceso a los que viven el problema, quienes se convierten en autores de la investigatión.

Essa abordagem, a pesquisa-ação, possibilita aos pesquisadores eao grupo de participantes, segundo TH IO LLEN T (1996, p.08), "os meios de se tornarem capazes de responder com maior eficiência aos problemas da situação em que vivem, em particular sob forma de diretrizes de ação transformadora." "O s pesquisadores, nesse tipo de pesquisa, "desempenham um papel ativo no equacionamento dos problemas encontrados, no acompanhamento e na avaliação das ações desencadeadas em função dos problemas." (p.15)

TH IO LLEN T (1996, p.16), considera que a pesquisaração é uma estratégia metodológica de pesquisa social, na qual:

- háuma ampla eexplícita interação entre pesquisadores e pessoas implicadas na situação investigada; 
- desta interação resultaa ordem de prioridadedos problemas a serem pesquisados e das soluções a serem encaminhadas sob forma de ação concreta;

- o objeto da investigação não é constituído pelas pessoas e sim pela situação social e pelos problemas de diferentes naturezas encontrados nesta situação;

- o objetivo da pesquisa-ação consiste em resolver ou, pelo menos, em esclarecer os problemas da situação observada;

- há, durante o processo, um acompanhamento das decisões, das ações e de toda a atividade intencional dos atores da situação;

- a pesquisa não se limita a uma forma de ação (risco de ativismo): pretendese aumentar o conhecimento ou o "nível de consciência" das pessoas e grupos considerados.

Para TH IOLLEN T (1987, p.100), a pesquisa-ação pode ser orientada em função da resolução de problemas, utilizando uma seqüência que não é rígida:

- identificar problemas rel evantes dentro da situação investigada;

- estruturar a explicação dos problemas;

- definir um programa de ação para a resolução dos problemas escolhidos como prioritários;

- acompanhar os resultados da ação por intermédio de diversos meios de controle (ver até que ponto o problema está sendo "resolvido" ou apenas "deslocado");

- fazer uma síntese dos resultados obtidos em todas as fases.

Para ANDRÉ (1995, p. 33), “a pesquisa-ação envolve um plano de ação, plano esse que se baseia em objetivos, em um processo de acompanhamento e controle da ação planejada e no relato concomitante desse processo."

N o processo da pesquisa-ação, os pesquisadores devem recorrer a métodos e técnicas de grupos para lidar com a dimensão coletiva da investigação, além de técnicas de registro, de processamento e de exposição dos resultados. As técnicas de questionários e de entrevista individual são utilizadas como meio de informação complementar.

$\mathrm{N}$ ão se dispensam outros tipos de técnicas, como: diagnóstico de situação, resolução de problemas, mapeamentos de representações etc. As técnicas didáticas, de divulgação e de comunicação, inclusive audiovisual, também fazem parte dos recursos da pesquisa-ação.

0 pesquisador precisa ter claro que o procedimento e o instrumento utilizado vai interferir no tipo de interpretação dos dados produzidos. Portanto, é imprescindível que o pesquisador avalie as condições de uso de cada técnica selecionada. 
As técnicas selecionadas devem permitir ao pesquisador organizar o raciocínio, estabelecendo interseção entreas idéias gerais e as comprovações produzidas no campo de pesquisa. N esse caso, estar-seá privilegiando uma análise qualitativa da realidade sem descartar os dados quantitativos, muitas vezes, necessários para fortalecer os argumentos.

0 planejamento da pesquisaração tem como ponto de partida uma "fase exploratória" e como ponto de chegada "a comunicação dos resultados". Intermediando estes dois grandes momentos ocorrem uma multiplicidade de caminhos que devem ser seguidos conforme as circunstâncias e o cronograma de atividades.

Portanto, deverá ser preocupação dos pesquisadores a pesquisa teórica, a organização do seminário, a sel eção dos métodos e das técnicas de pesquisa de campo, a organização dos instrumentos, a aplicação dos instrumentos, o cotejar do saber formal dos especialistas com o saber informal dos "usuários".

\section{Como está a proposta na prática?}

A coleta de dados, ora em desenvolvimento, vem possibilitando uma série de idéias e enfoques imprescindíveis ao estudo, resultantes da análise documental eiconográfica, da aplicação de questionários e da realização de entrevistas (semi-estruturadas).

Pela análise documental, estamos resgatando a memória das práticas sociais escolares e não-escolares sobre os interesses e iniciativas que têm integrado a gestão da formação de professores. N esse processo estão sendo analisados os projetos pedagógicos dos cursos de licenciatura.

A análise iconográfica vem possibilitando a complementação dos dados coletados por meio de outros procedimentos e de outros projetos.

A observação tem sido usada como mais um tipo de ferramenta que vem fornecendo informações que não foram possíveis de apreender com outros procedimentos e instrumentos no quetange ao tempo real e mesmo sobre o que foi produzido no tempo passado, mas que se atualiza ininterruptamente.

No que se refereà observação, éimportantelembrar que a intenção tem sido a de apreender o movimento do cotidiano, procurando identificar nas ações os movimentos que transparecem. Por isso, nesse procedimento, não partimos de esquemas predeterminados, fixos ou en quadrados aprioristicamente, mas procuramos estar alerta, anotando tudo que parece relevante para o movimento da teoria para a prática e desta para a teoria, pois como expliciata ALVES (1998, p. 10) 
Como pesquisadora do cotidiano, fui aprendendo que este nos indica possibilidades que escapam e não são vistas em um determinado momento. Precisamos, assim, guardar com carinho tudo o que vamos entendendo ou criando, mesmo que pareça não ser importante, em determinado momento.

A prática da observação não privilegia dia da semana, mas o processo de proposta pedagógica que está sendo implantado na PU CPR, desde 1998.

0 questionário, esta ferramenta, será aplicada para coletar todo tipo de informação, priorizando-se o que diz respeito às estratégias desencadeadas pela gestão dos processos de formação do professor.

Sobrea entrevista (semi-estruturada), éimportante destacar queela partiu de um roteiro preestabelecido pel o grupo. N este roteiro, cuidamos para que pontos fundamentais à abordagem não fossem esquecidos. Por meio deste procedimento, buscamos estabel ecer os primeiros contatos entre pesquisado e pesquisador, bem como estreitar os laços entre essas duas esferas constitutivas do processo de investigação. Ao mesmo tempo, temos claro que a entrevista será a al ternativa que garantirá a complementação dos dados colhidos em outras fontes e com outras técnicas.

No decorrer das entrevistas, aconteceram momentos em que uma simples conversa com os pesquisados foi transformada em parte da entrevista, pois al gumas vezes as informações destemomento vieram somar àquelas obtidas numa entrevista mais formal com a população sel ecionada para amostra.

Situações como estas são explicitadas por BO G D AN eBIKLEN (1997, p. 134) quando eles mostram o papel no investigador

N os estudos de observação participante, o investigador geralmente já conhece os sujeitos, de modo que a entrevista se assemel ha muitas vezes a uma conversa entre amigos. N este caso, não se pode separar facilmente a entrevista das outras atividades de investigação. (...) Por vezes, a entrevista não tem uma introdução; 0 investigador tranforma simplesmente aquela situação numa entrevista.

O s dados levantados pelos pesquisadores estão sendo sistematizados, levando sempre em conta as etapas da pesquisa e os procedimentos e instrumentos usados na coleta de dados. As informações colhidas estão sendo tematizadas em torno da problematização da pesquisa e, desse modo, 0 grupo está reunindo as principais provas encontradas no decorrer desta parte da investigação, as quais fornecem elementos significativos para a continuidade da pesquisa. 


\section{0 que fazer com as informações?}

0 desafio a que o pesquisador se propõe na pesquisa-ação éo de produzir novas formas de conhecimento e novas formas de relacionamento entre pesquisadorese epesquisadose destes com o saber. Para isso, a pesquisa-ação precisa ser conduzida dentro de questões teórico-práticas de investigação de orientação crítica.

No caso da pesquisa-ação, os "atores", nas ações investigadas, geram, utilizam informações, orientam ações e tomadas de decisões.

A interpretação dos fatos observados e dos dados colhidos será motivo de análise e interpretação dos pesquisadores, mas não poderão ser mobilizados por eles, pois este processo deverá ser constantemente submetido ao entendimento dos membros do grupo implicado. As interpretações não poderão ser realizadas com apoio no senso comum e nem nos impulsos dos participantes, mas suas sugestões deverão ser levadas em consideração pelos pesquisadores.

Todas as fontes documentárias deverão ser aproveitadas, as auto-avaliações e os dados levantados por meio de procedimentos e de instrumentos de pesquisa selecionados pelos pesquisadores.

Pelos dados já levantados e parcialmente analisados e interpretados, os elementos determinantes para referendar a análise documental estavam atrelados a uma interpretação de conceitos e procedimentos capazes de concretizar as inovações pretendidas.

A concepção de planejamento, a integração das ações, a participação da comunidade e a atualização, foram estudadas para que se pudesse determinar a visão da comunidade universitária, o grau de assimilação e conscientização na implementação do projeto.

O s dados sistematizados possibilitaram perceber que a concepção de planejamento ganha "diferentes conotações na visão da comunidade universitária (...) ora ele é confundido com o documento escrito, ora é entendido como processo de estabelecimento de objetivos e metas, (...) como se fosse um modismo" (ZAIN KO , 2001, p. 38). N o entanto, quando

é entendido como processo associado ao de avaliação institucional, que tem como busca fundamental a melhoria da qualidade da gestão universitária, 0 conceito de planejamento estratégico ganha consistência, porque é relacionado a uma ferramenta (instrumental técnico) indispensável para definição de políticas e para o sucesso do planejamento estratégico da instituição. (p. 39)

$\mathrm{N} \mathrm{a}$ anál ise das respostas dadas aos questionários e nas entrevistas (semiestruturadas) pode-se perceber a participação de todos os segmentos da comuni- 
dade, tanto no processo de concepção, como da implantação do projeto estraté gico e projeto pedagógico da PU CPR.

A utilização de diferentes procedimentos e instrumentos de pesquisa possibilitou reestruturar uma interpretação inicial sobre a comunidade universitária. O s primeiros dados mostravam um conceito multifacetado euma comunidade universitária dividida. Pela triangulação dos dados foi possível verificar que, tanto na análise da integração das ações como na participação da comunidade, houve um enorme envolvimento com o novo projeto pedagógico e com os planos setoriais, deixando evidente a conscientização da comunidade universitária sobre as missões e funções da PU CPR para o século XXI.

\section{Comunicando estudos}

Essa iniciativa, pesquisa e prática pedagógica, gerou mudanças. $0 \mathrm{~s}$ paradigmas vigentes precisaram ser rompidos, o confronto entre velhos conceitos e novos model os geram novas práticas pedagógicas. A exigência de um novo padrão de conhecimento exige educação/pesquisa/produção e transformação das relações dos indivíduos e dos grupos.

O primeiro seminário de educação - EDU CERE (2001), promovido pela Área de Educação da PU C PR, abriu espaço para que as pesquisas em desenvolvimento na PU CPR fossem discutidas eanalisadas, num processo democrático, que incorporou ações, que favoreceram as relações entre educação, pesquisa e conhecimento, além de fornecer aos participantes uma visão do futuro da I nstituição.

A experiência dos grupos de pesquisa durante o EDU CERE, com a difusão de idéias, favorecendo a aproximação das macrocompetências organizacionais e microcompetências individuais, coloca a PU CPR no caminho da modernização e, conseqüentemente, possibilita 0 atendimento às exigências da sociedade por uma universidade atuante no século XXI, ou seja, aquela que tem a missão de educar, de formar e de realizar pesquisas, mas, concomitantemente está atenta à função ética, à autonomia, à responsabilidade eà função preventiva.

\section{Notas bibliográficas}

1 Ver BRANDÃO, C. R. (O rg.). Pesquisa participante. São Paulo: Brasiliense, 1981. BRAN DÃO, C. R. (O rg.). Repensando a pesquisa participante. São Paulo: Brasiliense, 1987. D EM O, P. Pesquisa participante: mito e realidade. Rio de Janeiro: SEN AC, 1984. N O RO N H A, O . M. Pesquisa participante: respondo questões teórico-metodológicas. In: FAZEN D A, Ivani. (O rg.). M etodologia da pesquisa educacional. São Paulo: Cortez, 1991. 
2 Sobre a pesquisa-ação, ver THIO LLENT, M. N otas para o debate sobre a pesquisa-ação. In: BRAN D ÃO, C. R. Repensando a pesquisa participante. São Paulo: Brasiliense, 1984. TH IO LLEN T, M. M etodologia da pesquisa-ação. São Paulo: Cortez, 1996.

3 Sobre pesquisa etnográfica e estudo de caso, ver LÜ D KE, M ; AN DRÉ, M. E. D. A. Pesqui sa em educação: abordagens qualitativas. São Paulo: EPU , 1986. TRIVIÑ OS, A. N . S. Introdução à pesquisa em Ciências Sociais a pesquisa qualitativa em educação. São Paulo m: Atlas, 1990. FAZEN D A, I. (O rg.). M etodologia da pesqui sa educacional. São Paulo: Cortez, 1991. STAKE, R. Pesquisa qualitativa / naturalista: problemas epistemológicos. Educação e seleção, São Paulo, n. 7, p. 19-27, jun. 1983.

4 SERRAN O, G. P. Investigación cualitativa: retos e ininterrogantes. I. M étodos. M adri: Editorial La M uralla, 1994.

\section{Referências bibliográficas}

ALVES, R. Conversas com quem gosta de ensinar. 21. ed. São Paulo: Cortez: Autores Associados, 1985.

ALVES, R. Primeiralição para os educadores. Disponível em : <www.uol.com.br/ aprendiz>. Acesso em: 22 jun. 2001.

AN DRÉ, M. D. A . de. Etnografia da prática escolar. Campinas: Papirus, 1995. (Série prática pedagógica).

BO GDAN , R. ; BIKLEN , S. Investigação qualitativa em educação. Portugal: Porto, 1997.

CASTAN H O , S. E. M. Universidade entre o sim, o não e o talvez. Caderno de Pesquisa, n. 100, p. 37-48, mar. 2000

COSTA, M . V. Introdução: novos ol hares na pesquisa em educação. In:

C aminhos investigativos: N ovos ol hares na pesquisa em educação. Porto Ầ legre: M ediação, 1996. p. 7-17.

DECLARAÇÃO mundial para o ensino superior no século XXI. In: CON FERÊN CIA M UN DIAL SO BRE 0 EN SIN O SU PERIOR, 1998, Paris. Anais... Tendências da educação superior para o século XXI. Brasília: U N ESCO/CRUB, 1999. p. 15-32.

D EM O , P. Introdução à metodologia da ciência. 2. ed. São Paulo: Atlas, 1990.

D EM O, P. Pesquisa: princípios científico eeducativo. 2. ed. São Paulo: Cortez: Autores Associados, 1991. (Biblioteca de educação. Série I. Escola; v.11).

DEM O , P. Pesquisa e construção do conhecimento: M etodologia Científica no caminho de H abermas. Rio de Janeiro: Tempo Brasileiro, 1994. 
DEM O , P. Educação e qualidade. Campinas: Papirus, 1995a.

DEM O , P. Educar pela pesquisa. Campinas: Autores Associados, $1996 a$.

DEM O , P. Pesquisa e construção do conhecimento: metodologia científica no caminho de $\mathrm{H}$ abermas. 2. ed. Rio de Janeiro: Tempo Brasileiro, 1996b. (Biblioteca tempo universitário; 96).

FAZEN D A, I. (O rg.). M etodologia da pesquisa educacional. São Paulo: Cortez, 1991.

FAZEN D A, I. Novos enfoques da pesquisa educacional. São Paulo: Cortez 1992.

FAZEN D A, I. A pesquisa em educação e as transformações do conhecimento. Campinas: Papirus, 1995. (C oleção práxis).

FAZEN DA, I. C. A. (O rg.). Didática e interdisciplinaridade. Campinas: Papirus, 1998. (Coleção práxis).

LESSARD - HÉRBART, M . Pesquisaem educação. Lisboa: Instituto PIAGET, 1984.

LUD KE, M .; AN D RÉ, M . E. D . A. Pesquisa em educação: abordagens qualitativas. São Paulo: EPU, 1986. ( Temas básicos de educação e ensino).

M IRAN D A, M . G. de. N ovo paradigma de conhecimentos e políticas educacionaisna América Latina. In: VEIG A, I. P. A. ; CASTAN H O , M . E. L. M . (O rg.). Pedagogia universitária: a aula em foco. Campinas: Papirus, 2000. p. 13-47.

TARD IF, M. Saberes profissionais dos professores. In: . Elementos para uma epistemologia da prática profissional dos professores e sua consequêencias em relação à formação para o magistério. Pelotas: PU CRS, 1999. (Palestra)

THIO LLENT, M. N otas para o debate sobre a pesquisa-ação. In: BRAN DÃO, Carlos Rodrigues. Repensando a pesquisa participante. São Paulo: Brasiliense, 1984.

TH IO LLENT, M. M etodologia da pesquisaação. São Paulo: Cortez, 1996.

SANTOS, S. S. Um discurso sobre as ciências. 6. ed. Porto: Afrontamento, 1992.

SAVIAN I, D . O s saberes implicados na formação do professor. São Paulo: Ed. UNESP, 1996.

WACH OWICZ, L. A. (O rg.). A interdisciplinaridadena universidade. Curitiba: Champagnat, 1998. 
SEVERIN O A. J. Formação do educador e avaliação educacional. São Paulo: Ed. UNESP, 1999.

ZAIN KO , M . A. S. ; GISI, M . L. A gestão de competências: inovação ou modismo na formulação de políticas públicas. Revista D iálogo Educacional, Curitiba, v. 2, n.3, p.33-44, jan./jun. 2001.

Recebido em: 25/10/2001

A provado em: 12/11/2001 